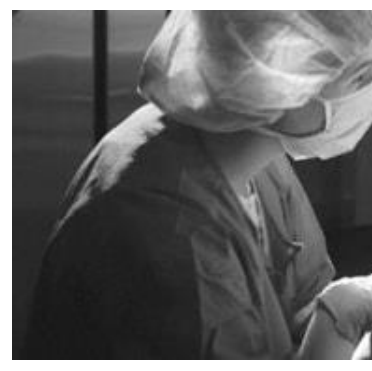

E-ISSN: 2616-3470

P-ISSN: 2616-3462

(C) Surgery Science

www.surgeryscience.com

$2020 ; 4(3): 272-273$

Received: 01-06-2020

Accepted: 07-07-2020

Diop A

General Surgery Department,

Idrissa Pouye General Hospital,

Dakar, Senegal, BP 3270 Dakar,

Senegal

\section{KA I}

General Surgery Department,

Idrissa Pouye General Hospital,

Dakar, Senegal, BP 3270 Dakar,

Senegal

\section{Mutombo D}

General Surgery Department,

University Clinic of Lubumbashi (D.C.R.)

\section{Faye AC}

General Surgery Department,

Idrissa Pouye General Hospital,

Dakar, Senegal, BP 3270 Dakar,

Senegal

\section{Diop PS}

General Surgery Department,

Idrissa Pouye General Hospital,

Dakar, Senegal, BP 3270 Dakar,

Senegal

\section{Fall B}

General Surgery Department,

Idrissa Pouye General Hospital,

Dakar, Senegal, BP 3270 Dakar,

Senegal

Corresponding Author:

Diop A

General Surgery Department,

Idrissa Pouye General Hospital,

Dakar, Senegal, BP 3270 Dakar,

Senegal

\section{International Journal of Surgery Science}

\section{Intestinal volvulus on Meckel's diverticulum: about an observation}

\author{
Diop A, KA I, Mutombo D, Faye AC, Diop PS and Fall B
}

DOI: https://doi.org/10.33545/surgery.2020.v4.i3e.505

Abstract

Meckel's diverticulum most often remains asymptomatic and is diagnosed only fortuitously or when complications arise. We report a case of intestinal volvulus on Meckel's diverticulum in a 19-year-old patient. The surgical procedure was an ileal resection with anastomosis. The postoperative follow-up was simple.

Keywords: Meckel's diverticulum, intestinal volvulus, resection, anastomosis

\section{Introduction}

Meckel's diverticulum is the partial persistence of the omphalo-mesenteric duct. It is the most frequent congenital anomaly of the gastrointestinal tract with a slight male predominance ${ }^{[1]}$. It most often remains asymptomatic and is diagnosed only fortuitously or when complications arise ${ }^{[2]}$. We report the case of a Meckel's diverticulum complicated by an intestinal volvulus.

\section{Case report}

He was a 19-year-old patient, referred by the national emergency medical services for the management of abdominal pain, vomiting and transit stop, the start of which started 24 hours ago. Its history was without particularity and its normal constants. The abdomen was slightly distended with a diffuse tenderness and a slight defense on palpation, no contracture or meteorism. An abdominal x-ray showed few sparse-type hydro-aeric levels [Figure 1]. CT scan showed a small bowel obstruction with junctional syndrome on a stenosing ileitis likely about 8 centimeters from the ileo-cecal junction (Figure 2). The diagnostic hypothesis retained was an upper intestinal obstruction. A laparoscopy had been indicated. The intraoperative discovery of intestinal volvulus on Meckel's diverticulum was the reason for the conversion to laparotomy during which the portion of the ileal loop containing the Meckel's diverticulum had been resected (Figure 3), followed by an ileo-ileal anastomosis. The part had been sent to anatomopathology for examination (Figure 4). The post-operative results were good and the patient returns at home on the fifth day post-operative.

Pathology results indicated Meckel's diverticulitis complicated by small intestinal inflammatory volvulus.

\section{Discussion}

Meckel's diverticulum is the most frequent congenital anomaly of the gastrointestinal tract with a slight male predominance ${ }^{[1]}$. It is rare and occurs between 2 to $4 \%$ of the population ${ }^{[3]}$. It most often remains asymptomatic and is diagnosed only fortuitously or when complications arise. In our case, it was a man who had an intestinal volvulus. It is necessary to know how to evoke the diagnosis of Meckel's diverticulum within the vast group of acute or subacute intestinal obstructions in particular in the young people without surgical history, because Meckel's diverticulum is difficult to identify despite the progress of imagery ${ }^{[1]}$. The location of Meckel's diverticulum 20 centimeters from the ileocecal valve joins the description made by Johann MECKEL as well as the occlusive strangulation mechanism ${ }^{[4,5]}$. The diverticulum consists of a mucous heterotopia, of the gastric type in 23 to $60 \%$ of cases; it may be a pancreatic type mucosa ${ }^{[6]}$. In the case presented, there was an intestinal resection taking away the Meckel's diverticulum with restoration of continuity. This technique is preferred to wedge resection, the risk of which is to leave ectopic tissue in place ${ }^{[7]}$. 
The postoperative follow-up was simple in our patient even if certain post-operative complications have been reported ${ }^{[8]}$

\section{Conclusion}

Meckel's diverticulum most often remains asymptomatic and is diagnosed only fortuitously or when complications arise. It is necessary to know how to recognize it in the diagnosis of acute abdominal pain for a better surgical management.

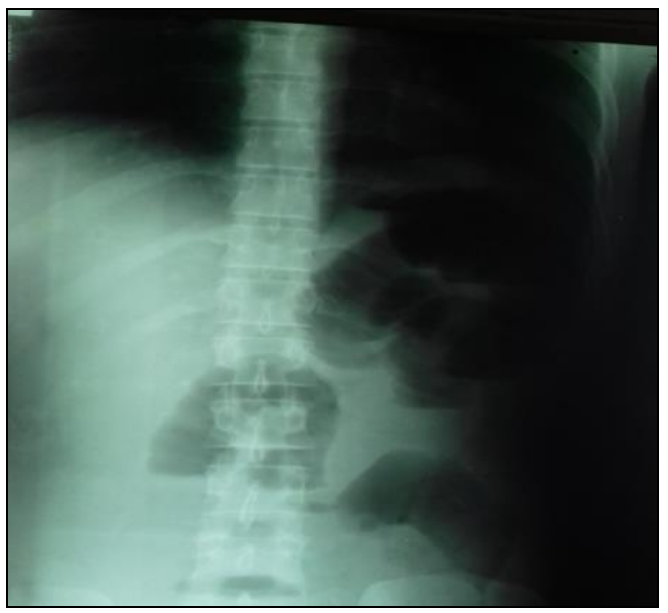

Fig 1: Abdominal X-ray showed hydroaeric levels

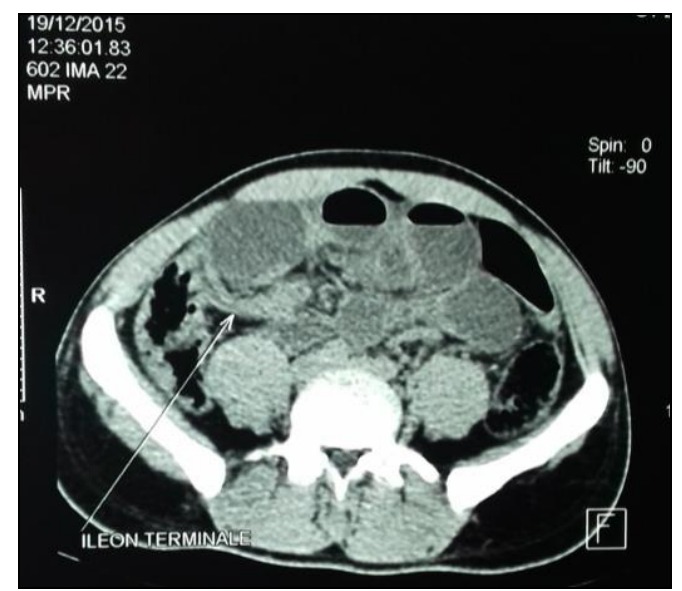

Fig 2: CT scan: intestinal obstruction with junctional Syndrome

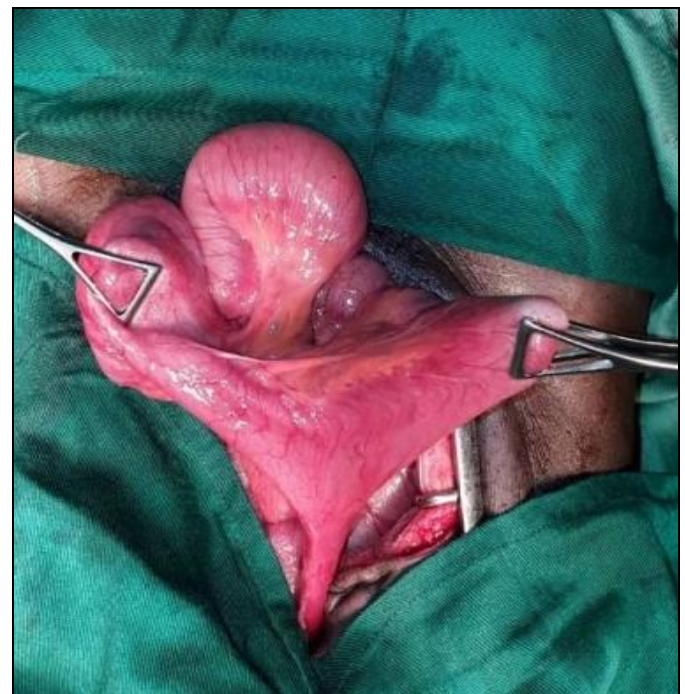

Fig 3: Intraoperative view of the intestinal volvulus on Meckel's diverticulum

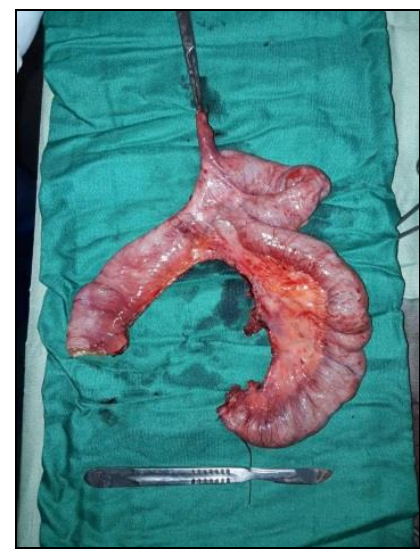

Fig 4: Resection piece carrying small bowel and diverticulum

\section{References}

1. Barbary C, Tissier S, Floquet M, Régent D. Imagerie des complications du diverticule de Meckel. J Radiol. 2004; 85(3):273-9.

2. Ouangré E, Zida M, Bazongo M, Sanou A, Patindé Bonkoungou G, Doamba ND. Complications du diverticule de Meckel (DM) chez l'adulte: à propos de 11 cas au CHU-Yalgado Ouédraogo au Burkina Faso. Pan Afr Med J. 2015; 22:74.

3. Hamma K, Iouknane D. Les occlusions intestinales aiguës chez l'adulte: étude rétrospective à propos de 75 cas de Janvier 2012 à Décembre 2013 au service de chirurgie générale. Université de Béjaia, 2014.

4. Schmutz G, Joidate A, Aube C, Phi IN, Provost N, Fournier $\mathrm{L}$ et al. Occlusion intestinale et diverticule de Meckel. FeuillRadiol. 2003; 43(3):223-40.

5. Beyrouti MI, Amar MB, Beyrouti R, Abib M, AYADI abib O. Complications du diverticule de Meckel : à propos de 42 cas. Tunis Médicale. 2009; 87(4):253-6.

6. Park JJ, Wolff BG, Tollefson MK, Walsh EE, Larson DR. Meckel Diverticulum: the Mayo Clinic Experience with 1476 Patients (1950-2002). Ann Surg. 2005; 241(3):529-33.

7. Grapin C, Bonnard A, Helardot PG. Chirurgie du diverticule de Meckel. EMC-Chirurgie. 2005; (2):613620.

8. Edgar Ouangré. Complications du diverticule de Meckel (CDM) chez l'adulte : à propos de 11 cas au CHU de Yalgado Ouédraogo au Burkina Faso. PanAfrMed J. 2015; 22:274. 